\title{
Perceived needs and satisfaction with care in people with multiple sclerosis: A two-year prospective study Charlotte Ytterberg*1, Sverker Johansson ${ }^{1}$, Kristina Gottberg2, Lotta Widén Holmqvist ${ }^{1}$ and Lena von Koch ${ }^{1}$
}

\begin{abstract}
Address: ${ }^{1}$ Department of Clinical Neuroscience, and Department of Neurobiology, Care Sciences and Society, Karolinska Institutet, Stockholm, Sweden and 2 Department of Neurobiology, Care Sciences and Society, Karolinska Institutet, Stockholm, Sweden

Email: Charlotte Ytterberg* - charlotte.ytterberg@ki.se; Sverker Johansson - sverker.johansson@ki.se; Kristina Gottberg - kristina.gottberg@ki.se; Lotta Widén Holmqvist - lotta.widen.holmqvist@ki.se; Lena von Koch - lena.von.koch@ki.se

* Corresponding author
\end{abstract}

Published: 29 September 2008

BMC Neurology 2008, 8:36 doi:10.1 186/147/-2377-8-36
Received: 7 April 2008

Accepted: 29 September 2008

This article is available from: http://www.biomedcentral.com//47/-2377/8/36

(C) 2008 Ytterberg et al; licensee BioMed Central Ltd.

This is an Open Access article distributed under the terms of the Creative Commons Attribution License (http://creativecommons.org/licenses/by/2.0), which permits unrestricted use, distribution, and reproduction in any medium, provided the original work is properly cited.

\begin{abstract}
Background: Considering the costs of multiple sclerosis (MS), it is crucial that the health-related services supplied are in accordance with needs as they are perceived by people with MS (PwMS). Satisfaction with care is related to quality of care and can provide health care providers with the means for improvement. The aim was to explore the perceived needs and satisfaction with care amongst PwMS over a two-year period, also taking sex and disease severity into consideration.
\end{abstract}

Methods: The sample consisted of 219 outpatients at a MS specialist clinic. Data on perceived needs and satisfaction with care were collected every six months using a questionnaire which included various dimensions of care. The data was analysed for the whole sample and on an individual level, as well as in subgroups with regard to sex and disease severity.

Results: There were no statistically significant variations in the proportion of PwMS with perceived needs concerning different health-related services during the study period. However, individual variations were found with regard to both perceived needs and satisfaction with care. Few PwMS perceived a continuous need for a specific service. However, the majority perceived a need for rehabilitation, assistive devices, transportation service for the disabled, psychosocial support/counselling and information on social insurance/vocational rehabilitation at least sometimes. Severe MS was associated with a greater perceived need for almost all the services studied and women experienced a need for psychosocial support/counselling to a greater extent than men. In relation to the different categories of health care staff, PwMS were most satisfied with nurses with regard to all dimensions of care. They were least satisfied with the availability of psychosocial support/counselling; and information about social insurance/vocational rehabilitation.

Conclusion: Despite the large proportion of individuals with mild disease severity in our sample, a considerable number of needs were identified of which many, on an individual level, varied over time. Key services demanded by PwMS were identified. Also the level of satisfaction with care varied and areas with a potential for improvement were identified such as the availability of rehabilitation services including an increase in the supply of psychosocial support and counselling. 


\section{Background}

Multiple sclerosis (MS) is a chronic, neurological disease, the onset of which usually occurs between the ages of 20 40 years. The disease results in a wide range of symptoms, but does not alter the life span substantially [1]. Consequently the majority of people with MS (PwMS) live with the disease for most of their lives and over a period of many years experience various needs for health-related services.

A recent study revealed that the great majority of PwMS in Stockholm make parallel use of hospital specialist care and primary care and that neurology care contacts constitute only $20 \%$ of all outpatient care [2]. The total cost of MS in Sweden is estimated at 600 million euro per year, of which direct costs account for $68 \%$ [3]. Considering the extensive costs of MS in terms of public spending, it is crucial that the health-related services supplied are effective and in accordance with needs as perceived by the PwMS. It has been shown that patients' and doctors' perceptions of disability in MS differ [4] and disabled people and their nominated key professionals have been found to perceive needs for health-related services differently [5]. It is therefore important to identify the needs that are perceived by the PwMS and to investigate their satisfaction with care.

Satisfaction with care is a complicated, multidimensional concept that includes both affective and cognitive components [6]. It is related to quality of care $[7,8]$ and can provide health care providers with the means for improvement. A number of studies have revealed that PwMS are dissatisfied with several areas of care e.g., rehabilitation, psychosocial counselling, adaptations, coordination between services and advice concerning MS-related matters [2,9-14]. However, few studies [9] have explored the variation in perceived needs and satisfaction with care over time in PwMS and potential differences between subgroups (e.g., with regard to sex and disease severity) have been sparsely studied $[9,11,14]$. Such knowledge is important for the planning of health-related services for PwMS to be able to meet perceived needs and optimise patient satisfaction.

The International Classification of Functioning, Disability and Health (ICF) aims to provide a scientific basis for the study of health conditions and is also useful for the study of health care systems, in terms of outcomes and the costeffectiveness of services, the assessment of needs and consumer satisfaction [15]. The ICF has two parts: 1) Functioning, including body functions/body structures, and activities and participation, 2) Contextual Factors, including environmental and personal factors, which determine the level and extent of the individual's functioning. Environmental factors e.g., health-related services, make up the physical, social and attitudinal environment; by not providing adequate health-related services, society may create environmental barriers instead of providing facilitators [15]. Satisfaction with care is not classified within the ICF framework but may be regarded as an environmental factor. For studies of satisfaction with care Ware et al. have proposed a theoretical framework which includes eight dimensions that should be assessed [16]. This taxonomy has previously been applied in several studies of people with neurological disorders $[2,17,18]$.

The aim of the present study was to explore perceived needs in relation to different health-related services, also taking sex and disease severity into consideration, and to explore PwMS's satisfaction with care over a two-year period.

\section{Methods \\ Participants and procedures}

The study was carried out in the context of a prospective, observational study of functioning and perceived health amongst PwMS [19]. Those eligible were all PwMS diagnosed according to the Poser criteria [20], who, during the period from February 1, 2002 to June 12, 2002, were scheduled for an outpatient appointment with one of two senior neurologists at the MS Centre of the Department of Neurology, Karolinska University Hospital, Huddinge, in Stockholm, Sweden. The PwMS received written and oral information about the study and were included after having given their informed consent. The PwMS were followed up every six months for two years, in the first place in conjunction with their regular visits to the senior neurologist, otherwise an appointment was made for datacollection on another day. At the time of inclusion and at 6, 12, 18 and 24 months, the PwMS met an investigator, one of five research physiotherapists, primarily the same investigator and at the same time of day on all occasions.

The neurologist responsible determined disease course and assessed disease severity by means of the Expanded Disability Status Scale (EDSS) [21]. EDSS-scores were categorized according to the Swedish MS-register as EDSS normal (0), EDSS mild (1.0-3.5), EDSS moderate (4.05.5) and EDSS severe (6.0-9.5) [22]. The remaining data was collected by the research physiotherapists. Demographic data and clinical characteristics were collected by means of interviews and from the medical records.

Data regarding perceived needs and satisfaction with care was collected using a questionnaire that has previously been used in studies of people with stroke [18], GuillainBarré syndrome [17] and MS [2]. The questionnaire was based on Ware's taxonomy [16], and included the dimensions of art of care (engagement/sympathy, kind treatment), accessibility, technical quality of care, finances, availability, continuity and efficacy/outcomes of care. The 
questionnaire has been found to be feasible including good face validity. In addition to the dimensions suggested by Ware, one item dealing with participation in planning care was included in a previous study of people with stroke [18], since patient participation is included in Sweden's Health and Medical Services Act. Furthermore, as a result of a pilot study exploring the feasibility of the instrument among PwMS [23], items dealing with diagnosis-related information and information about the disease were included in a previous population-based study of people with multiple sclerosis in Stockholm County [2]. The questionnaire consisted of 22 statements, which the PwMS were asked to agree or disagree with on a 5-graded Likert scale. The alternative "not applicable" was also presented. Data on all 22 items included in the questionnaire was collected on inclusion, whereas data regarding the ten items related to availability was collected on inclusion and at $6,12,18$ and 24 months. The items regarding availability consisted of ten statements concerning different health-related services e.g., physiotherapy, assistive devices and transportation services for the disabled. For each service, the PwMS were asked to choose between the alternatives "need" or "no need" and, for each service need indicated, they were asked to rate agreement on a 5graded Likert scale e.g., "I have received all the physiotherapy that I need".

The study was approved by the ethical committee of Karolinska Institutet in Stockholm, Sweden.

\section{Statistical analysis}

Descriptive statistics were used to present perceived need and satisfaction with care. Satisfaction with care was dichotomised into satisfied (1-2 on the Likert scale) or not satisfied (3-5 on the Likert scale). The Cohran Q test was performed for analyses of the changes in the proportion of PwMS with perceived needs during the study period with regard to different health-related services for the whole sample and for the subgroups, with regard to sex and disease severity. Chi square statistics were used for the analyses of differences in sex and disease severity between PwMS with perceived needs for different healthrelated services and those with no perceived need, and between PwMS who were satisfied with availability and those who were not. A p value $\leq 0.05$ was considered statistically significant. The statistical analyses were performed in Statistica 7.

\section{Results}

Of 255 eligible PwMS, 36 declined and 219 were included in the study. During the study period seven PwMS died and 12 withdrew, leaving 200 who were followed for two years. Demographic and clinical characteristics on inclusion are summarised in Table 1.
Table I: Demographic and clinical characteristics of PwMS on inclusion

\begin{tabular}{lc}
\hline & $\mathrm{n}(\%)$ \\
\hline People with MS & 219 \\
Women & $149(68)$ \\
Age, years & $47(12,20-75) *$ \\
Living with a partner & $152(69)$ \\
Working full or part time & $117(58)$ \\
Disease course: & \\
$\quad$ Relapsing remitting & $127(58)$ \\
$\quad$ Secondary progressive & $83(38)$ \\
$\quad$ Primary progressive & $9(4)$ \\
Disease severity: & \\
$\quad$ EDSS normal, 0 & $1(0.5)$ \\
$\quad$ EDSS mild, I-3.5 & $129(59)$ \\
EDSS moderate, 4-5.5 & $37(17)$ \\
EDSS severe, 6-9.5 & $52(23.5)$ \\
Time lapse since diagnosis, years & $14(10,0-44) *$ \\
Immunomodulatory treatment & $182(83)$ \\
\hline
\end{tabular}

* mean (SD, range)

† Working; used only for PwMS $<65$ years of age, the customary age for retirement in Sweden

Perceived need and PwMS's satisfaction with care on inclusion are presented in Table 2. All the PwMS preferred an early diagnosis but only around half were satisfied with the circumstances under which the diagnosis was delivered. Most PwMS were satisfied in areas concerning information about the disease, art of care (engagement/ sympathy, kind treatment) and accessibility, although fewer were satisfied with their contacts with psychologists and access to physicians. As far as the professional health care staff were concerned, these PwMS were most satisfied with nurses when it came to all dimensions of care. For the majority of the participants, all the expertise needed had been available, but most of those who perceived a need for information regarding social insurance/vocational rehabilitation and half of those who perceived a need for psychosocial support/counselling and rehabilitation periods had not received these services to the extent that they perceived necessary.

Despite the fact that most of the PwMS in the sample had mild EDSS, a high proportion perceived a need for physiotherapy (61\%); occupational therapy (41\%); and rehabilitation periods (a defined time-period of more intense rehabilitation at special rehabilitation units or in day care) $(42 \%)$. However, more than one third of those who perceived a need were not satisfied with these areas of rehabilitation. The costs of care were considered burdensome by $75 \%$. The vast majority wanted to participate in planning their care but only $63 \%$ of those who perceived a need to participate were satisfied. Regarding continuity and efficacy/outcomes of care, the majority were satisfied. 
Table 2: Perceived need and satisfaction with care of PwMS $(n=219)$ on inclusion

\begin{tabular}{|c|c|c|}
\hline Dimensions & Applicable/Perceived need, \% & Satisfied, \%* \\
\hline \multicolumn{3}{|l|}{ Diagnosis-related information } \\
\hline Want early diagnosis & 100 & $84 \dagger$ \\
\hline Content with situation in which the diagnosis was received & 100 & 57 \\
\hline \multicolumn{3}{|l|}{ Information regarding the disease } \\
\hline Physicians & 100 & 81 \\
\hline Nurses & 86 & 93 \\
\hline Occupational therapists & 37 & 70 \\
\hline Physiotherapists & 52 & 72 \\
\hline Welfare officers & 37 & 67 \\
\hline Psychologists & 13 & 54 \\
\hline Others & 28 & 77 \\
\hline \multicolumn{3}{|l|}{ Art of care } \\
\hline \multicolumn{3}{|l|}{ Engagement/sympathy from staff } \\
\hline Physicians & 100 & 82 \\
\hline Nurses & 89 & 88 \\
\hline Occupational therapists & 34 & 75 \\
\hline Physiotherapists & 50 & 85 \\
\hline Welfare officers & 35 & 76 \\
\hline Psychologists & 13 & 56 \\
\hline Others & 26 & 79 \\
\hline \multicolumn{3}{|l|}{ Kind treatment } \\
\hline Physicians & 100 & 90 \\
\hline Nurses & 90 & 96 \\
\hline Occupational therapists & 36 & 86 \\
\hline Physiotherapists & 53 & 88 \\
\hline Welfare officers & 35 & 85 \\
\hline Psychologists & 13 & 67 \\
\hline Others & 30 & 81 \\
\hline \multicolumn{3}{|l|}{ Accessibility } \\
\hline Physicians & 84 & 65 \\
\hline Nurses & 85 & 81 \\
\hline Occupational therapists & 28 & 78 \\
\hline Physiotherapists & 44 & 77 \\
\hline Welfare officers & 26 & 71 \\
\hline Psychologists & 9 & 55 \\
\hline Others & 23 & 77 \\
\hline \multicolumn{3}{|l|}{ Technical quality of care } \\
\hline Contact with all expertise needed & 98 & 82 \\
\hline Finances & 98 & 25 \\
\hline \multicolumn{3}{|l|}{ Availability } \\
\hline Physiotherapy & 61 & 65 \\
\hline Occupational therapy & 41 & 66 \\
\hline Rehabilitation periods & 42 & 58 \\
\hline Assistive devices & 45 & 80 \\
\hline Workplace adaptation & 28 & 70 \\
\hline Home adaptation & 34 & 79 \\
\hline Transportation service for the disabled & 42 & 89 \\
\hline Home help/Personal assistants & 21 & 66 \\
\hline Psychosocial support/counselling & 38 & 50 \\
\hline Information on social insurance/vocational rehabilitation & 40 & 29 \\
\hline \multicolumn{3}{|l|}{ Continuity } \\
\hline Meeting the same staff & 98 & 88 \\
\hline \multicolumn{3}{|l|}{ Participation in planning care } \\
\hline Want to participate in planning care & 95 & $85 \dagger$ \\
\hline Have participated in planning care & 79 & 63 \\
\hline \multicolumn{3}{|l|}{ Efficacy/outcomes of care } \\
\hline Hospital inpatient care & 48 & 80 \\
\hline Hospital outpatient care & 97 & 89 \\
\hline Primary care & 52 & 67 \\
\hline Rehabilitation periods & 32 & 78 \\
\hline
\end{tabular}

* Among those who perceived need

+ Agree 
During the study period there were no statistically significant variations over time in the proportion of PwMS with perceived needs concerning different health-related services; either in the whole sample or with regard to sex. In those with severe EDSS, a statistically significant variation was found concerning occupational therapy $(p=0.007)$. Table 3 presents those PwMS who, in the course of the study a) perceived needs of the different health-related services at all times (inclusion, 6, 12, 18 and 24 months), sometimes or never, and b) of those who perceived a need, the proportion of PwMS who were satisfied at all times, sometimes or never. Individual variations in per- ceived needs as well as in satisfaction with care were found regarding most health-related services. Few PwMS perceived a persistent need for a specific health-related service during the period of the study. However, the majority perceived a need for rehabilitation (physiotherapy - 85\%, occupational therapy - 62\%, rehabilitation periods $60 \%$ ), assistive devices (69\%), transportation service for the disabled (62\%), psychosocial support/counselling $(60 \%)$ and information on social insurance/vocational rehabilitation $(57 \%)$ at all times or sometimes. Of those who perceived a need at all times or sometimes, these PwMS were most satisfied with the availability of assistive

Table 3: Number of PwMS who during the study a) perceived needs of the different health-related services at all times (inclusion, 6, I2, 18 and 24 months), sometimes or never, and b) of those who perceived a need, the proportion of PwMS who were satisfied at all times, sometimes or never

\begin{tabular}{|c|c|c|c|c|}
\hline & \multirow[t]{2}{*}{ Need, n (\%) } & \multicolumn{3}{|c|}{ Satisfied, \% } \\
\hline & & All times & Sometimes & Never \\
\hline \multicolumn{5}{|l|}{ Physiotherapy } \\
\hline All times & $53(26)$ & 40 & 60 & 0 \\
\hline Sometimes & 118 (59) & 42 & 37 & 20 \\
\hline Never & $29(14)$ & & & \\
\hline \multicolumn{5}{|l|}{ Occupational therapy } \\
\hline All times & II (6) & 54 & 45 & 0 \\
\hline Sometimes & I $14(57)$ & 48 & 31 & 21 \\
\hline Never & $75(37)$ & & & \\
\hline \multicolumn{5}{|l|}{ Rehabilitation periods } \\
\hline All times & II (6) & 0 & 91 & 9 \\
\hline Sometimes & $110(55)$ & 40 & 29 & 31 \\
\hline Never & $79(40)$ & & & \\
\hline \multicolumn{5}{|l|}{ Assistive devices } \\
\hline All times & $10(5)$ & 50 & 50 & 0 \\
\hline Sometimes & $129(64)$ & 62 & 26 & 12 \\
\hline Never & $61(30)$ & & & \\
\hline \multicolumn{5}{|l|}{ Workplace adaptation } \\
\hline All times & I (0) & - & - & - \\
\hline Sometimes & $90(45)$ & 56 & 13 & 31 \\
\hline Never & $109(54)$ & & & \\
\hline \multicolumn{5}{|l|}{ Home adaptation } \\
\hline All times & $0(0)$ & - & - & - \\
\hline Sometimes & $104(52)$ & 58 & 18 & 24 \\
\hline Never & $96(48)$ & & & \\
\hline Transportation service for the disabled & $40(20)$ & 68 & 32 & 0 \\
\hline All times & $84(42)$ & 76 & 14 & 10 \\
\hline Sometimes & $76(38)$ & & & \\
\hline \multicolumn{5}{|l|}{ Never } \\
\hline \multicolumn{5}{|l|}{ Home help/Personal assistants } \\
\hline All times & $10(5)$ & 30 & 70 & 0 \\
\hline Sometimes & $73(36)$ & 46 & 23 & 30 \\
\hline Never & $117(58)$ & & & \\
\hline \multicolumn{5}{|l|}{ Psychosocial support/Counselling } \\
\hline All times & $4(2)$ & 0 & 75 & 25 \\
\hline Sometimes & $116(58)$ & 46 & 16 & 38 \\
\hline Never & $80(40)$ & & & \\
\hline \multicolumn{5}{|c|}{ Information on social insurance/vocational rehabilitation } \\
\hline All times & I (0) & 0 & 100 & 0 \\
\hline Sometimes & $113(56)$ & 24 & 14 & 62 \\
\hline Never & $86(43)$ & & & \\
\hline
\end{tabular}


devices; workplace adaptation; home adaptation; and transportation service for the disabled. PwMS were least satisfied with the availability of psychosocial support/ counselling; and information on social insurance/vocational rehabilitation. Among those who perceived a persistent need, the transportation service for the disabled was the only item where more PwMS were satisfied at all times than sometimes.

Women experienced a need for psychosocial support/ counselling to a greater extent than men $(p=0.04)$. Between PwMS with mild and severe EDSS there were statistically significant differences with more people among those with severe EDSS perceiving needs. PwMS with moderate EDSS did not differ in perceived needs from those with mild or those with severe EDSS. A severe state of MS was associated with a greater perceived need and a mild state of MS was associated with a smaller perceived need for the availability of almost all the health-related services studied: physiotherapy $(\mathrm{p}=0.004)$, occupational therapy $(\mathrm{p}=0.01)$, rehabilitation periods $(\mathrm{p}=0.008)$, assistive devices $(p=0.002)$, home adaptation $(p=0.04)$, transportation service for the disabled $(\mathrm{p}=0.002)$ and home help/personal assistants $(p<0.001)$. However, there were no associations between disease severity and perceived need for workplace adaptation, psychosocial support/counselling and information on social insurance/vocational rehabilitation; nor was there any association between satisfaction with care and sex or disease severity.

\section{Discussion}

This study explored the perceived needs and satisfaction with care over a period of two years at a MS specialist outpatient clinic, taking sex and disease severity into consideration. Individual variations were found with regard both to perceived needs and satisfaction with care. However, the majority of the participants perceived a need for rehabilitation, assistive devices, transportation service for the disabled, psychosocial support/counselling and information on social insurance/vocational rehabilitation at all times or sometimes. A severe state of MS was associated with a greater perceived need for almost all the healthrelated services studied and women experienced a need for psychosocial support/counselling to a greater extent than men.

The majority preferred an early diagnosis, a result which tallies with previous studies $[2,24]$. However, only around half were satisfied with the circumstances surrounding the presentation of the diagnosis. This finding might reflect the fact that some PwMS in the sample received their diagnosis many years ago at a time when the diagnostic process was slower than today. The stress associated with receiving a MS diagnosis [25] may also have a negative impact on the degree of satisfaction. Nevertheless, there is probably some potential for improvement with regard to the diagnostic situation and this possibility should be further explored.

Regarding contacts with the different health care providers, the PwMS were least satisfied with the psychologists with regard to such matters as information about the disease, art of care (engagement/sympathy, kind treatment) and accessibility. One possible explanation can be that contacts with psychologists will most likely include an assessment of cognitive functioning, which, for the individual, may be associated with feeling ill-at-ease [26].

Despite the fact that the PwMS met a neurologist every six months, as many as 35\% of them were not satisfied with the physicians' accessibility; this is a result in line with a previous study [2]. This finding might reflect a need for more frequent visits or telephone contacts but may also illustrate the fact that physicians are the gate keepers to many health-related services. Previous studies have recognised the need for more effective care coordination $[9,27]$. Future studies should identify the issues underlying the call for increased access to physicians and explore how these needs could best be met e.g., by involving a multiprofessional team or a designated care coordinator [28].

As far as the professional health care staff is concerned, the PwMS were most satisfied with nurses with regard to all the dimensions studied. A plausible reason for this result may be that the majority of these PwMS received immunomodulatory treatment, entailing repeated contacts with nurses for instructions and assistance with the injections. This frequent contact may lead to the nurses becoming care

coordinators.

Regardless of disease severity, the majority of those who indicated a need for information regarding social insurance/vocational rehabilitation had not received this service to the extent that they perceived necessary. In a country like Sweden, with a public social insurance system, an improved information service regarding these issues as well as access to vocational rehabilitation services that respond to individual needs [29] might be a facilitating environmental factor which could enable PwMS to work and might facilitate participation.

Only half of those who perceived a need for psychosocial support/counselling reported that they had received this service to the extent that they perceived necessary; this is in line with results from a previous study [2] and possibly reflects the fact that this kind of service is not only in poor supply within the public social insurance system in Sweden but is also mainly provided by private caregivers, meaning high costs for the individual. 
The cost of rehabilitation is relatively small. Nevertheless, a recent study of the costs of MS in Sweden revealed that the expenditure on rehabilitation was reduced from $8.6 \%$ in 1998 to $7.2 \%$ in 2005 [3]. Considering that large proportions reported a need for physiotherapy, occupational therapy, and periods of rehabilitation and that more than one third were not satisfied with the care situation, the rationale for the reduction in rehabilitation costs can be questioned.

The fact that the majority were burdened by the costs of care is probably primarily explained by the high proportion of individuals in our sample who were receiving immunomodulatory treatment. In addition, the costs of care are probably especially burdensome for the $42 \%$ in the sample who were not working.

The results derived from previous studies which reveal that PwMS exhibit high participation preferences $[2,30]$ were confirmed by the fact that the great majority in the present study wanted to participate in planning their care. Involving PwMS in decision-making is included in the NICE-guidelines [28] and an increase in the proportion of people (63\% in our sample) who actually participate in planning their care should be striven for.

During the study period there were no statistically significant variations in the proportion of PwMS with perceived needs with regard to various health-related services. However, over time, individual variations in perceived needs and in satisfaction with care were found. The reasons for these variations are not clear but might indicate that some needs are met or disappear while others vary as a consequence of the varying MS disease. All the same, variations in needs and satisfaction with care coincide with previous results concerning significant variations in functioning and disability in PwMS [31]. The results highlight the call for a flexible health care system that can provide services with a minimum delay and reduce the environmental barriers to optimized functioning.

In accordance with the NICE guidelines [28], a regular review of the individual's care needs should be offered. The majority perceived a need for rehabilitation, assistive devices, transportation service for the disabled, psychosocial support/counselling and information on social insurance/vocational rehabilitation at all points in time or sometimes, suggesting both that these are key services demanded by PwMS and also that evidence-based rehabilitation services e.g., exercise therapy [32], cognitive behavioural therapy [33] and multidisciplinary rehabilitation [34] should be provided more extensively in order to improve satisfaction with care.
PwMS who perceived a need at all times or sometimes, were most satisfied with the availability of assistive devices; workplace adaptation; home adaptation; and transportation service for the disabled, which indicates that the availability of these services may be considered as reasonably satisfactory within the Swedish health care system. However, these PwMS were least satisfied with the availability of psychosocial support/counselling; and information on social insurance/vocational rehabilitation which suggests a need for an increase in the supply of these services.

As can be expected, a severe state of MS was associated with a greater perceived need for almost all the healthrelated services studied; this result is in line with previous studies $[9,14]$. However, the fact that PwMS with a mild disease severity perceive a need for rehabilitation services to a lesser extent than those with a more severe state of MS might arise from expectations based on the way the health care system is structured to focus on symptomatic treatment rather than health promotion. The expectations and knowledge that PwMS have of the different health care providers' areas of expertise may have an impact on their perceived needs of different services as well as their satisfaction with care. Although a previous study revealed that a surprisingly large proportion of PwMS lack information about appropriate exercises [11], maintaining the level of functioning, with the assistance of e.g., a physiotherapist, may not be recognized as a need by PwMS with mild disease severity. PwMS risk a variety of secondary conditions, including physical deconditioning and weight problems [35], and a relationship between secondary conditions and health behaviour has been suggested $[36,37]$. Thus, as has been proved in a previous study [38], for people with disability a shift in focus from cure to care including health promotion, would presumably be effective in terms of outcome and costs.

The present study's major strengths were the longitudinal design and the low dropout rate in contrast to many previous studies in which postal questionnaires have been used $[9,11,13,14]$. Although the presence of a health professional may have influenced the responses, one advantage, considering that cognitive disability is common among PwMS, was the opportunity to explain the questionnaires. Furthermore, the professional's presence ensured that the questionnaires were filled in by the PwMS and not by proxies. In addition, the questionnaire included questions with different dimensions on both perceived needs and satisfaction with care. However, since our aim was to describe the perspective of the PwMS, we used a client-centred perspective and thus we do not know whether our results reflect the actual care received. Therefore, the present study should be complemented with a study of the use of care. Furthermore, the impact of met/ 
un-met perceived needs and level of satisfaction with care on functioning and health-related quality of life should be explored.

The results are probably representative for a MS specialist outpatient clinic but there may be differences between countries or regions in Sweden due to different structures in the health care systems. The level of satisfaction with care in the present study may be influenced by higher demands made by PwMS attending a specialist clinic. On the other hand, at such a clinic the potential for meeting the needs of the PwMS ought to be most favourable and opportunities for improvements e.g., enhanced availability of rehabilitation services, are excellent.

\section{Conclusion}

Despite the large proportions of individuals in our sample with mild disease severity, a considerable number of needs were identified of which many varied on an individual level over time. Rehabilitation, assistive devices, transportation service for the disabled, psychosocial support/ counselling and information on social insurance/vocational rehabilitation, seem to be key services demanded by PwMS. Also the level of satisfaction with care varied and areas with a potential for improvement were identified e.g., availability of rehabilitation services including an increase in the supply of psychosocial support/counselling as well as information on social insurance/vocational rehabilitation. Future research is needed to explore how the different needs of PwMS best should be met in terms of outcome and cost-effectiveness and, within the different dimensions, what levels of satisfaction with care can be considered as acceptable.

\section{Competing interests}

The authors declare that they have no competing interests.

\section{Authors' contributions}

CY participated in the design and coordination of the study, performed the statistical analysis and drafted the manuscript. SJ participated in the design and coordination of the study, and helped to draft the manuscript. KG participated in the design of the study and helped to draft the manuscript. LWH participated in the design of the study and assisted in drafting the manuscript. LvK participated in the design and coordination of the study and helped to draft the manuscript. All authors read and approved the final manuscript.

\section{Acknowledgements}

The authors wish to express their gratitude to the persons with MS participating and the staff of the MS Centre, Karolinska University Hospital, Huddinge, and to Professor Hans Link. Data collection was supported by an unrestricted grant from Biogen Idec. The study was funded by grants from the Board of Research for Health and Caring Sciences, the Health Care Sciences Postgraduate School, Karolinska Institutet, the Swedish Association for Persons with Neurological Disabilities, and the Swedish Research Council.

\section{References}

I. Weinshenker BG: Natural history of multiple sclerosis. Ann Neurol 1994, 36 Suppl:S6-I I.

2. Gottberg K, Einarsson U, Ytterberg C, Fredrikson S, von Koch L, Widén Holmqvist $L$ : Use of health care services and satisfaction with care in people with multiple sclerosis in Stockholm County. A population-based study. Mult Scler 2008, I 4:962-97I.

3. Berg J, Lindgren P, Fredrikson S, Kobelt G: Costs and quality of life of multiple sclerosis in Sweden. Eur J Health Econ 2006, 7(Suppl 2):75-85.

4. Rothwell PM, McDowell Z, Wong CK, Dorman PJ: Doctors and patients don't agree: cross sectional study of patients' and doctors' perceptions and assessments of disability in multiple sclerosis. BMJ 1997, 3 | 4: I580-I583.

5. Kersten P, George S, McLellan L, Smith JA, Mullee MA: Disabled people and professionals differ in their perceptions of rehabilitation needs. J Public Health Med 2000, 22:393-399.

6. Keith RA: Patient satisfaction and rehabilitation services. Arch Phys Med Rehabil 1998, 79:। I22-II 28.

7. Leonard KL: Is patient satisfaction sensitive to changes in the quality of care? An exploitation of the Hawthorne effect. J Health Econ 2007.

8. Rubin HR: Can patients evaluate the quality of hospital care? Med Care Rev 1990, 47:267-326.

9. Forbes A, While A, Taylor M: What people with multiple sclerosis perceive to be important to meeting their needs. J Adv Nurs 2007, 58: 1 I-22.

10. Bingham SC, Beatty PW: Rates of access to assistive equipment and medical rehabilitation services among people with disabilities. Disabil Rehabil 2003, 25:487-490.

II. Somerset M, Campbell R, Sharp DJ, Peters TJ: What do people with MS want and expect from health-care services? Health Expect 200I, 4:29-37.

12. Kersten P, George S, McLellan L, Smith JA, Mullee MA: Met and unmet needs reported by severely disabled people in southern England. Disabil Rehabil 2000, 22:737-744.

13. Vickrey BG, Edmonds ZV, Shatin D, Shapiro MF, Delrahim S, Belin TR, Ellison GW, Myers LW: General neurologist and subspecialist care for multiple sclerosis: patients' perceptions. Neurology 1999, 53:I190-I197.

14. Kraft GH, Freal JE, Coryell JK: Disability, disease duration, and rehabilitation service needs in multiple sclerosis: patient perspectives. Arch Phys Med Rehabil 1986, 67:164-168.

15. The International Classification of Functioning, Disability and Health 200I [http://www.who.int/classifications/icf]. World Health Organization Accessed January 3I, 2008

16. Ware JE Jr: Effects of acquiescent response set on patient satisfaction ratings. Med Care 1978, 16:327-336.

17. Forsberg A, de Pedro-Cuesta J, Widen Holmqvist L: Use of healthcare, patient satisfaction and burden of care in GuillainBarre syndrome. J Rehabil Med 2006, 38:230-236.

18. Holmqvist LW, von Koch L, de Pedro-Cuesta J: Use of healthcare, impact on family caregivers and patient satisfaction of rehabilitation at home after stroke in southwest Stockholm. Scand J Rehabil Med 2000, 32: I73-I79.

19. Johansson S, Ytterberg C, Claesson IM, Lindberg J, Hillert J, Andersson $M$, Widen Holmqvist L, von Koch L: High concurrent presence of disability in multiple sclerosis. Associations with perceived health. J Neurol 2007, 254:767-773.

20. Poser CM, Paty DW, Scheinberg L, McDonald WI, Davis FA, Ebers GC, Johnson KP, Sibley WA, Silberberg DH, Tourtellotte WW: New diagnostic criteria for multiple sclerosis: guidelines for research protocols. Ann Neurol 1983, I3:227-23I.

21. Kurtzke JF: Rating neurologic impairment in multiple sclerosis: an expanded disability status scale (EDSS). Neurology 1983, 33:|444-1452.

22. The Swedish MS-register [http://www.msreg.net]. Accessed January 3I, 2008

23. Gottberg K, Einarsson U, Fredrikson S, von Koch L, Holmqvist LW: Multiple sclerosis in Stockholm County. A pilot study of utilization of health-care resources, patient satisfaction with 
care and impact on family caregivers. Acta Neurol Scand 2002, 106:24I-247.

24. Janssens AC, de Boer JB, Kalkers NF, Passchier J, van Doorn PA, Hintzen RQ: Patients with multiple sclerosis prefer early diagnosis. Eur J Neurol 2004, I I:335-337.

25. Chalfant AM, Bryant RA, Fulcher G: Posttraumatic Stress Disorder Following Diagnosis of Multiple Sclerosis. J Trauma Stress 2004, 17:423-428.

26. Holdwick DJ Jr, Wingenfeld SA: The subjective experience of PASAT testing. Does the PASAT induce negative mood? Arch Clin Neuropsychol 1999, 14:273-284.

27. Kroll T, Neri MT: Experiences with care co-ordination among people with cerebral palsy, multiple sclerosis, or spinal cord injury. Disabil Rehabil 2003, 25: I I06-I I I4.

28. National Institute for Health and Clinical Excellence (NICE) [http://www.nice.org.uk]. Accessed 29 March, 2008

29. Sweetland J, Riazi A, Cano SJ, Playford ED: Vocational rehabilitation services for people with multiple sclerosis: what patients want from clinicians and employers. Mult Scler 2007, 13:1183-1189.

30. Hamann J, Neuner B, Kasper J, Vodermaier A, Loh A, Deinzer A Heesen C, Kissling W, Busch R, Schmieder R, et al:: Participation preferences of patients with acute and chronic conditions. Health Expect 2007, 10:358-363.

31. Ytterberg C, Johansson S, Andersson M, Widén Holmqvist L, von Koch L: Variations in functioning and disability in multiple sclerosis: a two-year prospective study. J Neurol 2008, 255:967-73.

32. Rietberg MB, Brooks D, Uitdehaag BMJ, Kwakkel G: Exercise therapy for multiple sclerosis. Cochrane Database Syst Rev 2005:CD003980

33. Thomas PW, Thomas S, Hillier C, Galvin K, Baker R: Psychological interventions for multiple sclerosis. Cochrane Database Syst Rev 2006:CD00443I.

34. Khan F, Turner-Stokes L, Ng L, Kilpatrick T: Multidisciplinary rehabilitation for adults with multiple sclerosis. Cochrane Database of Systematic Reviews 2007.

35. Coyle CP, Santiago MC, Shank JW, Ma GX, Boyd R: Secondary conditions and women with physical disabilities: a descriptive study. Arch Phys Med Rehabil 2000, 81:1380-1387.

36. Santiago $M$, Coyle $C$ : Leisure-time physical activity and secondary conditions in women with physical disabilities. Disabil Rehabil 2004, 26:485-494.

37. Stuifbergen AK, Blozis SA, Harrison TC, Becker HA: Exercise, functional limitations, and quality of life: A longitudinal study of persons with multiple sclerosis. Arch Phys Med Rehabil 2006, 87:935-943.

38. Ravesloot C, Seekins T, White G: Living well with a disability health promotion intervention: Improved health status for consumers and lower costs for health care policymakers. Rehabil Psychol 2005, 50:239-245.

\section{Pre-publication history}

The pre-publication history for this paper can be accessed here:

http://www.biomedcentral.com/1471-2377/8/36/prepub

Publish with Biomed Central and every
scientist can read your work free of charge
"BioMed Central will be the most significant development for
disseminating the results of biomedical research in our lifetime. "
Sir Paul Nurse, Cancer Research UK
Your research papers will be:
• available free of charge to the entire biomedical community
• peer reviewed and published immediately upon acceptance
• cited in PubMed and archived on PubMed Central
• yours - you keep the copyright
Submit your manuscript here:
http://www.biomedcentral.com/info/publishing_adv.asp

